\title{
Coronavirus disease 2019 crisis and intentional injuries: now is not the time to erode alcohol control policies
}

\author{
Shannon Lange ${ }^{1}$ (D) Charlotte Probst ${ }^{1,2} \cdot$ Jürgen Rehm ${ }^{1,3,4,5,6,7,8}$ \\ Received: 6 May 2020 / Accepted: 13 July 2020 / Published online: 5 August 2020 \\ (C) The Canadian Public Health Association 2020
}

\begin{abstract}
In Canada, and elsewhere, the coronavirus disease 2019 (COVID-19) crisis has resulted in a social, economic, and alcohol policy environment that is likely to contribute to a rise in intentional injuries, whether interpersonal or self-directed violence. Heavy drinking has been identified as an important risk factor for intentional injuries, and with the erosion of alcohol control policies on alcohol availability, heavy drinking is likely to increase. During a time of social isolation, economic loss, psychological distress, and reduced access to health services and support networks, all of which are catalytic factors for both intentional injuries and heavy alcohol use, what is needed is individualized and population-based preventive interventions aimed at reducing alcohol consumption, rather than decisions to increase certain forms of alcohol availability.
\end{abstract}

\section{Résumé}

Au Canada et ailleurs, la crise du coronavirus 2019 (COVID-19) a créé un environnement de politiques socioéconomiques et de politiques en matière d'alcool qui risque fort d'engendrer une hausse du nombre de blessures intentionnelles, qu'elles soient autoinfligées ou issues d'actes de violence interpersonnels. La consommation excessive d'alcool a été identifiée comme étant un facteur de risque important en ce qui a trait aux blessures intentionnelles, et compte tenu de l'érosion de politiques sur le contrôle de l'accessibilité à l'alcool, il est probable que la consommation excessive d'alcool s'intensifiera. Pendant une période d'isolement social, de pertes économiques, de détresse psychologique et de diminution de l'accès aux services de santé et aux réseaux de soutien, lesquels constituent des facteurs catalyseurs pour les blessures intentionnelles et la consommation excessive d'alcool, il faudrait optimiser les interventions préventives visant à réduire la consommation d'alcool à l'échelle individuelle et collective, au lieu de décider de favoriser certaines formes de l'accessibilité à l'alcool.

Keywords Alcohol availability $\cdot$ COVID-19 $\cdot$ Heavy alcohol use $\cdot$ Intentional injuries $\cdot$ Interpersonal violence $\cdot$ Suicidal behaviour

Mots-clés Disponibilité d'alcool · COVID-19 · consommation excessive d'alcool · blessures intentionnelles · violence interpersonnelle $\cdot$ comportement suicidaire

Shannon Lange

shannon.lange@camh.ca

1 Institute for Mental Health Policy Research, Centre for Addiction and Mental Health, Toronto, ON M5S 2S1, Canada

2 Heidelberg Institute for Global Health, Universitätsklinikum Heidelberg, Heidelberg, Germany

3 Dalla Lana School of Public Health, University of Toronto, Toronto, ON, Canada

4 Institute of Medical Science, University of Toronto, Toronto, ON, Canada
5 Campbell Family Mental Health Research Institute, Centre for Addiction and Mental Health, Toronto, ON, Canada

6 Department of Psychiatry, University of Toronto, Toronto, ON, Canada

7 Institute of Clinical Psychology and Psychotherapy \& Center of Clinical Epidemiology and Longitudinal Studies (CELOS), Technische Universität Dresden, Dresden, Germany

8 Department of International Health Projects, Institute for Leadership and Health Management, I.M. Sechenov First Moscow State Medical University, Moscow, Russian Federation 
In addition to the direct effects that the coronavirus disease 2019 (COVID-19) has on morbidity and mortality, the indirect effects as a consequence of social isolation, economic loss, psychological distress, and reduced access to health services and support networks must also be recognized and addressed. Although it has been acknowledged that such conditions are likely to increase intentional injuries (see, for example, Reger et al. 2020) - i.e., interpersonal violence (particularly domestic violence) and self-directed violence (suicidal behaviour) - a category of injury that costs Canadian society over $\$ 4$ billion annually (Parachute 2015), the recognition of the role of heavy drinking in this relationship has been limited.

In North America, alcohol sales have been designated as an "essential service", and in some provinces, territories and states, existing restrictions on home delivery and carryout have been loosened. The latter constitutes an erosion of alcohol control policies targeting alcohol availability. Coupled with the fact that the indirect consequences of the COVID-19 crisis can act as a catalyst to heavy alcohol use, greater availability has also been shown to impact drinking patterns and alcohol-related problems, including interpersonal and self-directed violence (Popova et al. 2009).

Specifically, through increasing aggression (Bushman and Cooper 1990), heavy drinking can lead to interpersonal violence (Jewkes 2002), and in the context of COVID-19, most likely to intimate partner violence and family violence given the social restrictions in place. A study analyzing emergency department data from 14 countries found that in over $30 \%$ of the violence-related injuries, alcohol consumption by the perpetrator was seen as causal (Cherpitel et al. 2012; for a short overview of the literature, see Nutt (2020)). With respect to suicidal behaviour, in 30 to $40 \%$ of deaths by suicide, the victim was under the influence of alcohol to the point of intoxication (Cherpitel, Borges, \& Wilcox, 2004). Furthermore, increases in drinking and long-term heavy use may increase the risk of developing an alcohol use disorder in some individuals. Alcohol use disorders in turn have been identified as a significant risk factor for suicidal behaviour, with a 3.1-fold higher risk for a suicide attempt and 2.6-fold higher risk for death by suicide among individuals with an alcohol use disorder being reported (Darvishi et al. 2015). Moreover, the number of days of heavy drinking by married or cohabiting alcohol-dependent men has been found to be a significant predictor of whether or not severe episodes of violence occur in their intimate relationships (Murphy et al. 2001).

Although heavy drinking, interpersonal violence, and suicidal behaviour are complex phenomena in and of themselves, arising from a multitude of factors, they are linked (Brady 2006; Foran and O'Leary 2008). Therefore, with respect to intentional injuries, addressing heavy drinking is one prevention opportunity that can be enhanced during the COVID-19 crisis.
Such interventions should be implemented on two distinct levels - the individual level and the population level. Pertaining to the former, brief interventions, which can be remotely delivered, are an effective way to reduce heavy drinking (Donoghue et al. 2014). Furthermore, alcohol control policies can lead to a reduction in heavy drinking (Babor et al. 2010). Thus, there should be a reconsideration of the current categorization of alcohol sales as an essential service, and alcohol as an essential good, in Canada and elsewhere. In other parts of the world, restrictions on the availability of alcoholic beverages have increased, including a temporary ban of sales in some countries like Thailand, South Africa, and in parts of Europe (Rehm et al. 2020). In fact, in South Africa, the number of rapes and aggravated assaults have reportedly decreased by over $80 \%$ in the last month, which has been attributed in part to the complete ban of alcohol (Dörries 2020). In the context of North America, at a minimum, during the COVID-19 pandemic, alcohol policies that increase availability via carryout and delivery services should not be implemented. But, there are also policies that could be implemented to reduce alcohol availability rather than eliminate it entirely, such as reduced hours of sale and outlet restrictions (e.g., limiting the types of retail stores allowed to sell alcohol).

Accordingly, the erosion of alcohol control policies is likely to have significant consequences with respect to intentional injuries during the COVID-19 pandemic, especially in the context of social isolation, economic loss, psychological distress, and reduced access to health services and support networks. At a time when the healthcare system is already heavily burdened, precautionary measures should be taken to reduce any additional burden from largely preventable alcoholattributable conditions such as alcohol-induced intentional injuries. In Canada, more than $20 \%$ of drinkers aged 18-54 years have reported increased alcohol use during the COVID-19 crisis (NANOS Research 2020). Therefore, we urgently need to increase education and awareness of the relationship between heavy drinking and intentional injuries, on the population level, given that we are currently facing a time when heavy alcohol use may increase. Rapid research is needed on the immediate and sustained effects of increasing alcohol availability on intentional injuries during the COVID19 crisis to inform decision-makers with best practices in subsequent waves of infection.

\section{Compliance with ethical standards}

Conflict of interest The authors declare that they have no conflict of interest. 


\section{References}

Babor, T., Caetano, R., Casswell, S., Edwards, G., Giesbrecht, N., Graham, K., Grube, J., Hill, L., Holder, H., Homel, R., Livingston, M., Österberg, E., Rehm, J., Room, R., \& Rossow, I. (2010). Alcohol: No ordinary commodity. Research and public policy (2nd ed.). Oxford: Oxford University Press.

Brady, J. (2006). The association between alcohol misuse and suicidal behaviour. Alcohol and Alcoholism, 41(5), 473-478.

Bushman, B., \& Cooper, H. (1990). Effects of alcohol on human aggression: an integrative research review. Psychological Bulletin, 107(3), 341-354.

Cherpitel, C. J., Borges, G. L., \& Wilcox, H. C. (2004). Acute alcohol use and suicidal behavior: a review of the literature. Alcoholism, Clinical and Experimental Research, 28(5 Suppl), 18S-28S.

Cherpitel, C. J., Ye, Y., Bond, J., Room, R., \& Borges, G. (2012). Attribution of alcohol to violence-related injury: self and other's drinking in the event. Journal of Studies on Alcohol and Drugs, 73(2), 277-284.

Darvishi, N., Farhadi, M., Haghtalab, T., \& Poorolajal, J. (2015). Alcohol-related risk of suicidal ideation, suicide attempt, and completed suicide: a meta-analysis. PLoS One, 10(5), e 0126870.

Donoghue, K., Patton, R., Phillips, T., Deluca, P., \& Drummond, C. (2014). The effectiveness of electronic screening and brief intervention for reducing levels of alcohol consumption: a systematic review and meta-analysis. Journal of Medical Internet Research, 16(6), e142.

Dörries, B. (2020). Wie das Alkoholverbot Südafrika verändert thow the alcohol ban is changing South Africa]. Süddeutsche Zeitung. Available from https://www.sueddeutsche.de/panorama/suedafrikaalkohol-coronavirus-1.4891856?reduced=true.
Foran, H. M., \& O’Leary, K. D. (2008). Alcohol and intimate partner violence: a meta-analytic review. Clinical Psychology Review, 28(7), 1222-1234.

Jewkes, R. (2002). Intimate partner violence: causes and prevention. The Lancet, 359, 1423-1429.

Murphy, C. M., O'Farrell, T. J., Fals-Stewart, W., \& Feehan, M. (2001). Correlates of intimate partner violence among male alcoholic patients. Journal of Consulting and Clinical Psychology, 69(3), 528540.

NANOS Research. (2020). COVID-19 and increased alcohol consumption: NANOS poll summary report. Ottawa ON, Canada: Canadian Centre on Substance Use and Addiction. Available from https:// www.ccsa.ca/sites/default/files/2020-04/CCSA-NANOS-AlcoholConsumption-During-COVID-19-Report-2020-en.pdf.

Nutt, D. (2020). Drink? The new science of alcohol and your health. London: Yellow Kite.

Parachute. (2015). The cost of injury in Canada. Toronto ON, Canada: Parachute. Available from https://parachute.ca/wp-content/uploads/ 2019/06/Cost_of_Injury-2015.pdf.

Popova, S., Giesbrecht, N., Bekmuradov, D., \& Patra, J. (2009). Hours and days of sale and density of alcohol outlets: impacts on alcohol consumption and damage: A systematic review. Alcohol and Alcoholism, 44(5), 500-516.

Reger, M. A., Stanley, I. H., \& Joiner, T. E. (2020). Suicide mortality and coronavirus disease 2019-a perfect storm? JAMA Psychiatry. Epub ahead of print.

Rehm, J., Kilian, C., Ferreira-Borges, C., Jernigan, D., Monteiro, M., Parry, C. D. H., Sanchez, Z. M., \& Manthey, J. (2020). Alcohol use in times of the COVID 19. Implications for monitoring and policy. Drug and Alcohol Review, 39(4), 301-304.

Publisher's note Springer Nature remains neutral with regard to jurisdictional claims in published maps and institutional affiliations. 